\title{
Del Zoon Politikón al Zoon Elektronikón. Una reflexión sobre las condiciones de la socialidad a partir de Aristóteles
}

\author{
Vicente HUICI URMENETA \\ Escuela Universitaria de Magisterio Begoñako Andra Mari, BAM \\ Centro adscrito a la Universidad de Deusto / UNED-Bergara \\ vhuici@bergara.uned.es \\ Andrés DaVILA LeGERÉN \\ Universidad del País Vasco / Euskal Herriko Unibertsitatea \\ andres.davila@ehu.es
}

Recibido: 21-10-2015

Aceptado: 20-06-2016

\section{Resumen}

Aristóteles, en su Política, caracterizó al ser humano como un animal social (zoon politikón) que tenía la capacidad singular no sólo de expresar sentimientos sino también valores, por medio del lenguaje (éjon lógon). Estos principios de socialidad han constituido una de las piedras de toque más relevantes en todas las discusiones posteriores acerca del vínculo societario del ser humano. El breve ensayo que se presenta trata de evaluar la vigencia de los postulados del filósofo en la actualidad, en el contexto de una sociedad globalizada económicamente, pero también interconectada por las TIC y las redes sociales. Asimismo, pretende esbozar un reajuste de la figura humana para la que se propone la denominación de zoon elektronikón.

Palabras clave: Aristóteles; socialización; TIC's; neurociencia social; zoon elektronikón.

\section{From Zoon Politikón to Zoon Elektronikón. A Reflection on the Conditions of Sociability from Aristotle}

\begin{abstract}
Aristotle, in his Politics, characterized the human being as a social animal (zoon politikón) which had the unique ability not only to express feelings but also values, through language (éjon lógon). These principles of sociability have been one of the most important points of reference for all subsequent discussions on the social link. This paper tries to assess the validity of the philosopher's postulates today, in the context of an economically globalized society, but also interconnected by social networks. It also aims to outline a readjustment of the human figure for which is proposed the denomination of zoon elektronikón.
\end{abstract}

Key words: Aristotle; socialization; information and communications technologies; ICT; social neuroscience; zoon elektronikon.

\section{Referencia normalizada}

Huici Urmeneta, V. y A. Davila Legerén (2016): “Del Zoon Politikón al Zoon Elektronikón. Una reflexión sobre las condiciones de la socialidad a partir de Aristóteles", Política y Sociedad, 53 (3), pp. 757-772.

Sumario: Introducción. 1. Aristóteles y su Política. 2.Zoon politikón, zoon éjón lógon. 3. Mujeres, esclavos, niños y bárbaros. 4. La crítica del Zoon politikón éjon lógon. 5. Las mujeres y la crítica feminista. 6. El 
zoon politikón y las neurociencias. 7. El zoon politikón y la aparición de las TIC's. 8. El zoon elektronikón.

9. Conclusión: El zoon elektronikón ¿una nueva transformación de la humanidad? 10. Bibliografía

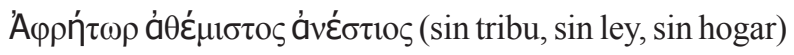

(Aristóteles, Política, 1253a)

\section{Introducción}

La atención que Enrique Gómez Arboleya dispensó a las obras clásicas del pensamiento político, y particularmente a las de Aristóteles (Arboleya, 1952), ha servido de punto fundamental de referencia a la hora de abordar la presente investigación teórica.

El objetivo principal de la misma ha sido retomar la caracterización del ser humano de Aristóteles, denominado en la Política como zoon politikón, zoon ejón logon, en tanto que analizador (Lapassade, 1971) de nuestras sociedades contemporáneas en tiempos de nuevos descubrimientos de la neurociencia social y de la implantación de las Tecnologías de la Información y el Conocimiento (TIC). Dicha caracterización del ser humano introduce una serie de contradicciones que nos permite enunciar ciertas determinaciones de la situación de tales sociedades, que en esta investigación adoptan la forma de diversas reflexiones cotangentes, como por ejemplo las referidas a la cuestión del género, que se han convertido en objetivos secundarios.

Por otra parte, de tal "efecto analizador" (Lourau, 1970) ha derivado la propuesta de definir al ser humano contemporáneo occidental u occidentalizado como un zoon elektronikón, que desplaza una parte de sus características anteriores, estructurales y dinámicas, hacia diversas prótesis externas.

En todo caso, nuestra propuesta metodológica parte de una concepción de la institución en movimiento, para cuyo análisis se ha procedido por medio de un sistema analógico que ha permitido la puesta a prueba efectiva de los dispositivos discursivos aristotélicos, que no de Aristóteles como analista, sin pretender, por otro lado, afianzar una perspectiva filológica, histórica o genealógica (Foucault, 1970), sino tan sólo plantear el alcance de una elucidación sociológica.

\section{Aristóteles y su Política}

Aristóteles, en el capítulo 2 del libro II (1253a) de su Política, caracterizó al ser humano como un animal social (zoon politikón), ubicando en el mundo de los dioses o en el reino de los animales a quien no se podía acoger a esta definición. 
Asimismo, describió al ser humano como poseedor de un lenguaje (éjon lógon) que tenía la capacidad de expresar no sólo sentimientos, como otros animales, sino también conceptos y valores.

No obstante, y dadas las circunstancias históricas de su tiempo, Aristóteles excluyó de su definición de ser humano a las mujeres, a los esclavos, a los niños y también a los extranjeros, como ha sido puesto de manifiesto en varios estudios (Moreno, 1988; Iriarte, 2002).

Durante muchos siglos esta propuesta aristotélica ha constituido la piedra de toque de numerosas discusiones filosóficas.

En la actualidad, una vez extendida la definición de ser humano a aquellos individuos de la sociedad originariamente excluidos, el desarrollo de las Neurociencias, de las Tecnologías de la Información y el Conocimiento (TIC's) y la globalización, de la mano de internet y de las redes sociales, han aportado nuevas perspectivas.

Así, la discusión puede retomarse ahora en un nuevo contexto, reflexionando acerca de la actual configuración del ser humano como zoon elektronikón.

La perspectiva desde la que se aborda esta nueva variante interpretativa, tiene en cuenta, en la medida de lo posible, los registros neurocientíficos, históricos y filosóficos, pero es fundamentalmente sociológica.

\section{Zoon politikón, zoon éjon lógon}

Si nos atenemos a los textos aristotélicos, se puede observar que la definición del ser humano como zoon politikón (más exactamente, como $\pi \mathrm{o} \lambda \iota \tau \iota \kappa o ̀ v ~ \zeta \tilde{\varphi} o v)$ en la Política, viene a ser la culminación de la expresión del vínculo con una forma de convivencia superior. Francisco Samaranch comenta, al respecto, que la definición del hombre como animal político "implica la vinculación natural con una forma comunitaria específica, la Pólis" (Samaranch, 1982: 679), acentuando las anteriores definiciones de la Ética Eudemiana en las que se habla del hombre como animal comunitario (koinomikón) o animal doméstico (oikonomikón).

Enrique Gómez Arboleya insiste en este aspecto, pues la Pólis resulta, para él "la comunidad política pura y simple" (Gómez Arboleya, 1952: 72), si bien supone un tipo de organización en la que la preeminencia de los lazos naturales ligados al clan, da paso a una mayor relevancia del vínculo territorial. Desde su punto de vista, la Pólis "es una noción de Derecho público" en la que "el Derecho de la tribu no se niega, pero se absorbe en un Derecho superior: el de la ciudad" (op. cit.: 73). Además, la pertenencia a la Pólis forja la homonoia, un a modo de unidad en el pensar y sentir que, bajo un protector divino -como Atenea en el caso de Atenas-, genera "una religión de seglares, ligada estrechamente con el Estado" (op. cit.: 75) subsumiendo lo religioso y lo patriótico.

De este sentir es también Juan Aranzadi quien relaciona la Pólis con la perspectiva holista de Aristóteles, subrayando que, más que ser un medio, "posee su propio e intrínseco fin" (Aranzadi, 1991: 84); es decir, que la Pólis no agrupa a sujetos prepolíticos en relación a un fin político, sino que genera dichos sujetos como tales desde sí misma, siendo esta su principal función. 
Y esto es así hasta tal punto que, frente a nuestra concepción individualista, los seres humanos de la época "no se concebían a sí mismos sin la referencia de la ciudad-estado, de la Pólis" (López Eire, 2000, 72).

Aristóteles vinculó, por otro lado, la humanidad del ser humano a la peculiar característica de ser, entre los animales, el único que tiene logos ( $\lambda$ ó yov $\delta \dot{\varepsilon} \mu$ póvov

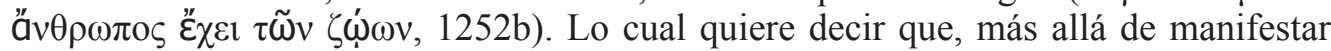
sentimientos, el ser humano es capaz de expresar valores abstractos: "Esto es lo propio de los humanos frente a los demás animales: poseer, de modo exclusivo, el sentido de lo bueno y lo malo, lo justo y lo injusto, y las demás apreciaciones" (1253a).

Dicha característica, y esto es importante, le adviene al ser humano de la "participación comunitaria", tratándose, por lo tanto, de algo aprendido, toda vez que "por naturaleza, la ciudad es anterior a la casa y a cada uno de nosotros" (1253a). Tales valores abstractos, en consecuencia, serían inculcados según variables históricas y políticas en la medida en que los individuos participaran en la vida de la comunidad, desde su iniciación educativa hasta su validación ciudadana. Como recuerda Aristóteles: "Nadie va a discutir que el legislador debe tratar muy en especial de la educación de los jóvenes; y, en efecto, si no se hace así en las ciudades se daña su constitución política, ya que la educación debe adaptarse a ella" (1337a).

Por todo lo apuntado, se puede comprender que para Aristóteles "el desarrollo de la pólis sea paralelo al desarrollo del logos" (Gómez Arboleya, 1952: 81), ya que no habría pólis sin logos, ni logos sin pólis.

\section{Mujeres, esclavos, niños y bárbaros}

Por lo demás, de las palabras subsiguientes del Estagirita, queda bastante claro que el núcleo duro de esta definición de ser humano es el varón griego, adulto y con plenos derechos. Quedan, así, fuera de este restringido ámbito masculino, en primer lugar aquellos que pueden ser considerados más que un ser humano (un dios: $\theta \varepsilon$ cós) o menos (un animal: $\theta \eta \rho i ́ o v) ~(1253 a)$, pero también otras figuras sociales muy notables.

Así ocurre con los esclavos, que sólo son contemplados como mera fuerza de trabajo. Pues, como deja bien claro Aristóteles, "el que es capaz de prever las cosas con su mente naturalmente es gobernador y señor o jefe, y el que es capaz de hacer esas cosas con su cuerpo es naturalmente súbdito o esclavo" (1252a). El esclavo es, en este sentido "una posesión animada" (1253b), un "hombre que no se pertenece por naturaleza a sí mismo" (1254a), alguien que "participa de la razón en tal grado como para reconocerla, pero no para poseerla" (1254b); "una parte", en fin, "del amo, como si fuera una parte animada, y separada de su cuerpo" (1255b).

Por otro lado, quienes no pertenecen al ámbito cultural griego, es decir los bárbaros, ( $\beta \alpha \rho \beta a ́ p o t)$, son asimilados a los esclavos, ya que "por naturaleza, bárbaro y esclavo son la misma cosa" (1252b).

Y, como se ha apuntado, también las mujeres y los niños están excluidos de este núcleo duro: "El varón, en efecto, es por naturaleza, más apto para el mando que la mujer -excepto en algunos casos en que la unión se haya realizado de una manera contraria a la naturaleza-, y la persona más anciana y más desarrollada o formada es 
también más apta para el mando que la que es más joven e inmadura"; (...) "la relación entre varón y hembra (...) mantiene una desigualdad permanente" (1259b).

De manera que, según resume Aristóteles, "la mayor parte de los seres gobiernan u obedecen por naturaleza. En efecto, el hombre libre gobierna al esclavo, el varón gobierna a la mujer, y el padre gobierna a los hijos" (1260a).

En el caso de las mujeres, como ha demostrado la profesora Ana Iriarte, el orden masculino "no se basa tanto en un aislamiento completo de la mujer cuanto en la captación que supone otorgar a ésta el papel, al tiempo secundario e imprescindible, de testigo" (Iriarte, 2002: 49). Y, al respecto, sería suficiente ciertamente con recordar el rol que, por ejemplo, Aristófanes atribuye a las mujeres en obras como Lisístrata o Las Asambleístas (Aristófanes, 1986), comedias en las que las féminas emergen como contraste y a la vez calco de los varones.

\section{La crítica del Zoon politikón éjon lógon}

La figura propuesta por Aristóteles ha sido respetada y matizada en la tradición occidental durante muchos siglos.

Así, el filósofo Tomás de Aquino (1225-1274), cumbre del pensamiento escolástico cristiano, asumió como propia, en su Summa Theologica, la definición de que "el hombre es por naturaleza animal social" (Tomás de Aquino, 2001: C.97 a.1) concibiendo también al ser humano como "una creatura intermedia entre los animales y los ángeles" (C.75). De igual manera, afirmó que "la operación propia del hombre en cuanto hombre es la de entender, pues por ella supera a todos los animales" (C. 76 a.1), teniendo en cuenta que "el lenguaje es el signo del pensamiento" (C.58 a.4) sin hacer más precisiones, pero recogiendo las distinciones fundamentales.

René Descartes (1596-1650), por su parte, en su célebre Discurso del Método, repitió que "la capacidad de juzgar bien y de distinguir lo verdadero de lo falso, que es lo que propiamente se denomina buen sentido o razón, es naturalmente igual en todos los hombres" (Descartes, 1986: 5-8: 29) y "que nos hace hombres y nos distingue de las bestias" (op. cit., 22-23: 30). También relacionó la capacidad de pensar y de juzgar moralmente con el lenguaje, pues "es cosa muy señalada que no hay hombres, tan torpes y tan estúpidos, sin exceptuar siquiera a los dementes, que no sean capaces de coordinar diversas palabras y de componer un discurso por el que den a entender sus pensamientos; $y$, por el contrario, no hay ningún otro animal, por perfecto y privilegiado de nacimiento que sea, que haga algo semejante (op. cit., 407-441: 98). Aun así, Descartes no se pronunció sobre la exclusión de las mujeres y adoptó una actitud muy similar a la aristotélica en el caso de los niños.

En el caso de G.F.W. Hegel (1770-1831), la crítica versó fundamentalmente sobre el régimen de esclavitud, condición necesaria de "la bella democracia" griega para permitir a los hombres libres participar en la vida ciudadana, pero, al cabo, un gran obstáculo para el reconocimiento de "que el hombre pueda pensarse como universal", y por lo tanto "libre" y "dotado de razón" (Hegel, 1982: 460). Por otro lado, Hegel continuó manteniendo en algunos de sus escritos la relevancia del aparato estatal sobre el individuo hasta hacer depender la existencia de este último del mismo 
Estado. En este sentido, algunas afirmaciones de Aristóteles resuenan en Hegel de una manera manifiesta. Así, cuando se aborda la cuestión de la educación, se dice en la Política que "ninguno de los ciudadanos se pertenece a sí mismo, sino todos a la ciudad" (1337a), y en su obra Filosofía del Derecho, el filósofo alemán apuntó que "el individuo mismo tiene objetividad, verdad y ética sólo como miembro del Estado" (Hegel, 1968: 212).

Para el marxismo, más allá de la inversión materialista de los valores hegelianos (o, a lo mejor, por ello mismo), el vínculo societario de los individuos continuó siendo una constante y, por ejemplo, ya en la Contribución a la Crítica de la Economía Política Karl Marx (1818-1893) afirmó que "en la producción social de su vida, los hombres establecen determinadas relaciones necesarias e independientes de su voluntad, relaciones de producción que corresponden a una fase determinada de desarrollo de sus fuerzas productivas materiales" (Marx, 1849).

De igual manera, Martin Heidegger (1889-1976), en su caracterización del ser humano como "ser-ahî", relacionó el lenguaje y la convivencia, afirmando que "hablar es articular significativamente la comprensibilidad del ser-en-el-mundo, al que es inherente el ser-con y que se mantiene en cada caso en un modo determinado del seruno-con-otro" (Heidegger, 1982: 180). Aun así, y reconociendo la matriz filosófica

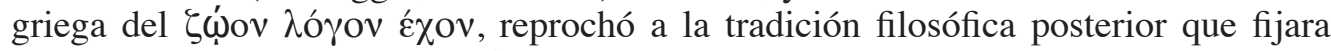
"preferentemente la vista en el $\lambda$ ó $o \varsigma$ como proposición" (op. cit.: 184), favoreciendo una interpretación logicista y gramatical de esta expresión, sin tener en cuenta todas las dimensiones del habla.

Por su parte, y para finalizar con este breve recorrido histórico, en los albores del pensamiento sociológico, Émile Durkheim (1858-1917) también reconoció el papel de la sociedad en la conformación de los individuos hasta el punto de presentar los hechos sociales como "modos de actuar, de pensar y de sentir, exteriores al individuo y que están dotados de un poder de coerción en virtud del cual se imponen a él" (Durkheim, 1988: 58).

\section{Las mujeres y la crítica feminista}

Con el transcurrir de los años, las figuras no reconocidas por Aristóteles como poseedoras de los rasgos fundamentales de humanidad, han ido incorporándose, en algunos casos tras largas luchas y muchas dificultades, al ámbito que anteriormente tan sólo estaba reservado a los varones libres y adultos.

En el mundo occidental la esclavitud desapareció de derecho tras la Convención de 1926, aunque de hecho muchas situaciones laborales pudieran evocar las terribles condiciones del esclavismo. Sin ir más lejos, la situación social de muchos trabajadores tras la recesión económica que comenzó en 2008 recuerda, en ocasiones, situaciones supuestamente periclitadas. Tal es también el caso de las críticas condiciones afrontadas por los millones de inmigrantes que sin derecho a la circulación deambulan, por diferentes motivos, por el globo terráqueo, señalándoseles como unos nuevos "bárbaros" y generando continuas variaciones en la política exterior e interior de los gobiernos. 
Por otro lado, diversos protocolos muy recientes han reconocido los derechos de los niños, y la lucha contra la pederastia y la pornografía infantil preocupa y ocupa a la opinión pública, a los Estados y a las Iglesias.

Pero, sin duda, el hecho más novedoso e importante de los últimos años ha sido la incorporación de la mujer al ámbito de la plena humanidad, como poseedora de derechos y deberes. Un hecho importante porque ha transformado la dinámica de la economía, la política y la sociedad, pero también porque ha forjado y continúa desarrollando una discusión ideológica que va más allá de la cuestión del género, poniendo en solfa, entre otros aspectos, toda la construcción aristotélica y sus consecuentes derivaciones.

Así, la crítica feminista no sólo ha dejado claro el patriarcalismo aristotélico, algo que ya había sido reconocido por historiadores y filósofos: "Aristóteles lo único que hace es servir al sistema patriarcal autoritario en el que él mismo se ha educado, intentando derivar de principios absolutos unos simples hechos", apunta Samaranch (1982: 676, nota); sino que dicha crítica ha llevado su argumentación hasta el punto de afirmar, por ejemplo, que "el yo del razonamiento abstracto constituye la primera trampa conceptual que conduce a una epistemología sexista o androcéntrica" (María Ángeles Durán en Moreno, 1988: 25).

Lo que así se ha puesto en duda, no ha sido, por lo tanto, tan sólo el conjunto de definiciones aristotélicas anteriormente apuntadas, sino todo el sistema conceptual subyacente en el que "la trascendencia sería así un <invento> de los varones para hacerse valer entre ellos $\mathrm{y}$, sobre todo, frente a las mujeres, cuyas vidas serían <intrascendentes>" (Celia Amorós, en Moreno, 1988: 9).

El profesor Emmánuel Lizcano ha confirmado en sus estudios parte de la crítica aludida, desplazando el punto de vista desde la perspectiva feminista hacia la Sociología del Conocimiento y articulándolo en la cuestión de la relación entre las metáforas y el pensamiento conceptual.

Así, frente a una explicación un tanto plana y meramente neurocientífica de la capacidad simbolizadora del cerebro humano como "semántica del lenguaje" (Redolar, 2014: 208), Lizcano ha propuesto un socioanálisis del lenguaje metafórico, demostrando que lo que habitualmente se entiende como conceptos precisos, claros y distintos, no son sino metáforas depuradas una y otra vez y articuladas muy arbitrariamente (y muy interesadamente): "La mayoría de los conceptos científicos se nos presentan no en su hacerse sino como "hechos", como términos propios y no como términos de una metáfora original constitutiva", pues "el concepto es útil en la práctica científica ordinaria precisamente cuando se olvida su carácter de concepto, es decir, cuando se olvida que ha sido previamente concebido, y concebido metafóricamente" (Lizcano, 2005: 150).

Es de esperar que esta línea de crítica de las bases aristotélicas, que ya asoma incluso en relación a la lógica binaria (Kosko, 2000), dará mucho de sí en el futuro, toda vez que se despliega abarcando multitud de dimensiones. 


\section{El zoon politikón y las neurociencias}

Por otro lado, en la actualidad y desde diversas disciplinas, se continúa defendiendo el carácter social del ser humano. Por ejemplo, una de las más recientes, la neurociencia social o neurosociología afirma que "humans are fundamentally a social species" (Decety y Cacioppo, 2011: 3), insistiendo en una dinámica plural e interrelacionada entre genes, funcionamiento cerebral y medio ambiente.

Uno de sus máximos impulsores, el neurobiólogo de la Universidad de Padua y descubridor de las denominadas células-espejo, Giacomo Rizzolatti, parte, por ejemplo, de esta afirmación fundamental, anteriormente impensable desde su disciplina: "Somos criaturas sociales y nuestra supervivencia depende de entender las intenciones y emociones de los demás" (Feito, 2007). Y, en efecto, algunos comportamientos que antes se vinculaban a la deliberación generada por supuestas áreas decisivas del cerebro humano-como los lóbulos frontales-, en la actualidad parecen responder a automatismos generados por un tipo de células y de neurotransmisores que, entre otras funciones, facilitarían la socialidad.

$\mathrm{Al}$ respecto, no está de más mencionar la denominada hipótesis del cerebro social que postula que el proceso de socialización de los seres humanos "ha favorecido el desarrollo de determinadas partes de la neocorteza, como la región prefrontal medial o la unión temporoparietal, regiones que desempeñan un papel clave en la cognición social" (Redolar, 2014: 694).

Tampoco está de más indicar, en relación al lenguaje como conformador de socialidad, que la teoría motora de la percepción del habla humana defiende que "mientras el oyente percibe el lenguaje, estaría empleando parte de la misma maquinaria neural que usa en la producción motora del lenguaje" (op. cit., 23).

Como ya se ha expuesto en otro lugar, el descubrimiento de las células fusiformes, así como de las denominadas células-espejo, junto a la constatación de la importancia de la dopamina como activador interrelacional, ha abierto la posibilidad de afirmar la existencia de "una base neuronal para la explicación de determinados actos que se llevarían a cabo en contextos sociales específicos sin mayor intervención ejecutiva de los participantes, actos en los que la capacidad imitativa operaría de motu proprio, garantizando la sociabilidad" (Huici, 2013: 158-159).

\section{El zoon politikón y la aparición de las TIC's}

A lo anterior, habría que añadir la importancia de la aparición de las nuevas tecnologías de la información y el conocimiento (TIC's), accesibles por medio de smartphones, tablets u ordenadores, lo que ha supuesto una vuelta de tuerca a todas estas cuestiones, ya que ha conllevado una serie de relevantes transformaciones en el ámbito psicosocial, afectando a todos los colectivos sociales en medio de un ambiente de euforia electrónica (Leung, 2007) cuando no en un a modo de " murmullo" o "parloteo" permanentes (Serres, 2014: 54-55). Entre las transformaciones más reseñables se pueden citar las siguientes.

En primer lugar, el uso de las TIC ha generado una alteración del vínculo con la percepción espacio-temporal habitual. Hasta ahora la mediación espacio-temporal 
estaba ritmificada socialmente según unos parámetros ritualizados (Halbwachs, 1994; Huici, 2007), pero las TIC suponen una disponibilidad permanente en el tiempo así como la desubicación espacial sistemática: se puede recurrir a las mismas desde cualquier lugar y en cualquier momento. Tal disponibilidad parece haber acelerado vertiginosamente las dinámicas sociales, pero sobre todo ha creado la posibilidad de la simultaneidad relacional asincrónica, abriendo "un espacio de encuentro de personas que objetivamente no pueden coincidir" y generando lo que Betty Martínez Ojeda (2006: vi-vii) denomina "espacios de flujos".

Pero, por otro lado, la ilusión de que basta "hacer clic" para acceder a las expectativas de cualquier dispositivo digital de interacción no hace sino alimentar "el mito de la transparencia de las interfaces", como si éstas proveyesen de "un lugar transparente y neutral donde el sujeto interactúa de manera automática con un texto, ya sea escrito o multimedia" (Scolari, 2004: 15). La deconstrucción de dicho mito requiere entender que las interfaces que usamos, nos modelan a su vez, habida cuenta que "el uso de un dispositivo interactivo no sólo transforma a los sujetos que participan de la interacción: toda la red socio-técnica se va modificando" (op. cit., 232), debiéndose, por tanto, abordar la dimensión social de las interfaces, en lugar de atenerse a la dimensión micro de la interacción.

En segundo lugar, desde un punto de vista neuropsicológico, es constatable la relevancia creciente de la memoria de trabajo o a corto plazo sobre la memoria a largo plazo. De hecho, la memoria a largo plazo se desplaza a los discos duros o a las nubes electrónicas, precisándose tan sólo de recursos a corto plazo para activar los contenidos y relaciones fundamentales. La profusión de herramientas como el PowerPoint, y la generalización del uso de presentaciones electrónicas en forma de sucesión de diapositivas (que pueden incluir imágenes, textos, hipervínculos, etc.) promueven tanto un "estilo cognitivo" (Tufte, 2006) como una "retórica universal" (d'Huy, 2007) que hacen aparecer el mundo "condesado, simplificado y más llano, brillante e hiperreal" (Frommer, 2011: 15). En este sentido, la idea de la externalización de la memoria como uno de los logros de las TIC confunde, quizás interesadamente, "la memoria de trabajo con la memoria a largo plazo" (Carr, 2011: 232), aunque ya no haya garantías de recuperar esa información en el futuro debido al "deterioro de los soportes donde se almacena la información y la desaparición de los programas para interpretarla" (Criado, 2015: 6); es la propia fragilidad tecnológica respecto a la materialización de la memoria lo que hace que el acto hoy en día tan habitual de "publicar en la red puede ser como escribir en la arena. Si nada lo remedia, avanzamos hacia una era paradójicamente oscura, con mucha información y poca memoria (...) [pues] la memoria digital es un bien muy volátil" (Lafuente, 2007: 263-264).

En tercer lugar, se aprecia una confusión progresiva entre el feed-back multisensorial y el feed-back electrónico. En efecto, las nuevas generaciones, educadas desde su infancia en el mundo electrónico, tienden a tomar como real empírico lo que aparece en las pantallas según diferentes formatos, sean estos verbales, acústicos o visuales. Tan sólo la constatación efectiva de la diferencia, puesta en evidencia en los encuentros vis a vis individuales o colectivos, muestra la consecuencias, a veces penosas, de la confusión. Tiempo ha, en los años ochenta, ya se anticipaba que estos sofisticados 
instrumentos se habían convertido en depositarios de "una singular esperanza: la de compensar frustraciones o carencias de un modo de vida" (Horacio C. Reggini en Turkle, 1984: 10), aun cuando las TIC ofrecían "con su capacidad de reacción e interacción, una compañía donde están ausentes la reciprocidad y la complejidad de una relación humana" (op. cit., 27).

De ahí la banalización de la escucha -tanto oral como alfabética (De Kerckhove: 125-145)- mediante la metáfora conversacional que convierte en indistinguibles el oír y el ver, como se expresa en la generalización del término "chat room" para dar cuenta de un lugar de encuentro virtual, en el que se presume una interacción -en línea o sincronizada entre internautas- que se desarrollará a la manera de una charla o de la cháchara, esto es, de un intercambio verbal de carácter informal. Una idea que se mantiene en la traducción de dicha expresión al francés en tanto que "salon de discussion" e igualmente en la traducción al castellano como "sala de charla", y en cambio desaparece de la expresión canadiense equivalente, a saber: "clavardoir", pues en ésta se hace explícito que en todo caso se trata de una conversación por escrito (bajo el modo " 'talk' using text") o, dicho de otro modo, de un hablar mediante un teclado (ya que se trata de un término, inventado en los años 90, resultado de la contracción de las palabras "clavier" -teclado- y "bavardoir" -que a su vez surge de la contracción de las palabras "bavarder": charlar o cotillear, y "parloir": locutorio-).

En cuarto lugar, se observa una valoración ascendente de la conexión sobre la comunicación: estar conectados o conectadas tiene tanta mayor relevancia en la medida en que se pueda cuantificar e independientemente del aspecto cualitativo de la comunicación. Las conexiones, las redes y todos los núcleos de información compartida -y convenientemente pagada- adquieren valor por sí mismos. Así, por ejemplo, "los adolescentes, si dejan de enviar mensajes, corren el riesgo de volverse invisibles "(Carr, 2011: 146), socialmente hablando. No en vano, la pantallización del mundo determina que "poco o nada se ve si no está en pantalla. Lo que importa se muestra en pantalla y, si no se muestra, no importa, no existe" (Block de Behar, 2009: 135). A su vez, conforma nuestro actual entorno tecnoperceptivo, en el que la hiperconectividad agota la atención, impidiendo la concentración.

En quinto y último lugar, el carácter expansivo de las TIC tiende a generar una dinámica sin fin de auto-demanda de servicios, como ya se advirtió precozmente en aquellos casos en que se instalaba un sistema de computación y a continuación, e independientemente de las necesidades para las que había sido instalado, se procedía "inventando trabajo a fin de usarlo" (Turkle, 1984: 22). De hecho, al cabo de unos años, "ya no necesitamos tener ocupados a los computadores ya que son ellos quienes nos mantienen ocupados" (Turkle, 2011: 279) con su interminable oferta de servicios desde todo tipo de soportes, aplicaciones y actualizaciones.

\section{El zoon elektronikón}

Todas estas transformaciones están dinamizando la constitución de nuevos tipos de subjetivación, diferentes de los hasta ahora conocidos, pues, como ha señalado la 
psicóloga Sherry Turkle, "las TIC no solamente están cambiando nuestra manera de hacer, sino también nuestra manera de ser" (Turkle, 2010).

El modo de subjetivación que poco a poco se va imponiendo viene a ser el de un individuo en red, permanentemente conectado, desubicado espacio-temporalmente, cuyo ámbito de socialidad se vincula a su propia activación en la red para lo cual no necesita sino una limitada memoria de trabajo. Todo ello conlleva "la alteración de las células cerebrales y la liberación de neurotransmisores, fortaleciendo gradualmente nuevas vías neuronales" (Carr, 2011: 149) que asientan el nuevo modelo.

A la vista de estas transformaciones, ¿dónde queda el zoon politikón éjon lógon, más allá de las críticas anteriormente aludidas?

El zoon politikón éjon lógon se estaría convirtiendo progresivamente en un zoon elektronikón, es decir, en un animal en el que el vínculo social se articularía cada vez más desde dispositivos electrónicos.

De hecho, tal zoon elektronikón sería la vertiente sociológica de un homo digitalis contemplado desde el punto de vista tecnológico. Insistiendo en la acepción de "digitalis" menos desde la perspectiva de la articulación y el procesamiento de la información de los softwares, y más desde la evolución instrumental, Fernando Sáez Vacas ha explicado meridianamente que el protagonismo técnico de la mano, iniciado con el homo habilis, acaso se habría actualizado en la Sociedad del Conocimiento, alimentado por instrumentos de aplicaciones inteligentes, por lo que "tras miles de horas usando diversos artefactos infotecnológicos" se habría adquirido "una asombrosa destreza doblemente digital (manejabilidad con los dedos), siendo conscientes de los efectos funcionales del dispositivo manejado" (Sáez Vacas, 2011:2). Esta perspectiva por limitada y novedosa que pudiera parecer, debería ser tenida en cuenta toda vez que podría suponer un hito desde el punto de vista sociobiológico.

En cualquier caso, el zoon elektronikón parecería igualar a todos los seres humanos por medio del acceso a la tecnología. Pues, en efecto, varones, mujeres, inmigrantes o autóctonos, incluso niños o niñas pueden entrar en el mundo de las TIC sin otras limitaciones que su capital cultural previo (Bourdieu, 1997) -acaso ya no tan escalado como antes-, su capacidad económica y la posibilidad de acceso al tejido electrónico. Todo lo cual debería ser analizado detenidamente pues, a pesar de no resultarnos ajena la posibilidad de caracterizar a una nueva humanidad como "pulgarcita" a tenor de sus habilidades a la hora de generar y acceder a información electrónica -sin ir más lejos mediante el uso de sus pulgares- (Serres, 2014), por otro lado, es constatable que "el acceso a la Red dista mucho de ser universal, pues hay un gran sector de la humanidad que no dispone de ordenador o de conexiones" (Bachiller, 2015: 3)

Así mismo, la Pólis de este nuevo zoon elektronikón, sería una Pólis electrónica, un tanto ajena al vínculo geográfico y al tiempo histórico y creando "una nueva forma espacial o región socio cultural" (Martínez, 2006: vii). Se parecería, de hecho, más a una Comunidad que a una Asociación (en los términos de Tonnies, 1979). En ella el feedback físico, base articuladora de los procesos de socialización tradicionales, habría sido parcial o totalmente sustituido por el feed-back electrónico, que se presentaría como natural por naturalizado socialmente. Como afirma el actor que encarna a Sean Parker -fundador de Napster y co-presidente de Facebook- en plena euforia de una fiesta con 
groupies menores de edad y cocaína en el film La red social: "We lived on farms and then we lived in cities, and now we're going to live in the Internet" ["Vivíamos en granjas, luego vivimos en ciudades y ahora vamos a vivir en internet"] (TSN 1:43:53). Se tornaría, así, todavía más acusada la obsolescencia del espacio y el tiempo, a la que ya se refería Günter Anders en 1959 mediante su evocación del país de Jauja, "en el que no habría distancias; es decir, seríamos a-espaciales (...) [Y] dado que no estaríamos destinados a hacer, actuar o esperar y todo tendría lugar "al instante", no habría ninguna demora, es decir, seríamos a-temporales" (Anders, 2011: 333).

Así mismo, el Logos de este zoon elektronikón parecería deshacerse de su condición abstracta o moral en la medida en que la conexión resulta un valor superior a la comunicación. En este sentido, la nueva Pólis favorecería de nuevo el sentido comunitario de un contacto acaso superficial pero suficiente, en el que la pérdida de la conexión sería la situación más grave y problemática. Todo ello independientemente de que la conectividad permanente impida en la mayoría de las ocasiones disponer "del tiempo indispensable para procesar toda la información que (se) recibe, y mucho menos para reflexionar sobre ella" (Bachiller, 2015: 2).

Y, por fin, la memoria, transferida a la exterioridad, tan sólo sería reclamada puntualmente con ocasión de abscesos identitarios ocasionales. En este ambiente de "vida liquida" (según la acepción de Bauman, 2013), la memoria de la individualidad sería paradójicamente comunitaria y se configuraría y reconfiguraría en un flujo permanente.

La normalización del zoon elektronikón vendría avalada por la excepcionalidad de la anormalidad correspondiente, es decir, de la patología consensuada. Sin duda es bien perceptible que la conectividad permanente, base de articulación de todo lo expuesto anteriormente, genera "un estado de alerta permanente" (Bachiller, 2015) debido a la sobreexcitación a la que se exponen los sujetos, así como la decepción que supone la falta de conectividad. Pero, a otro nivel, no se puede dejar de mencionar que, por ejemplo, según Kimberly Young, del Center for online Addiction de Pennsylvania, ya se han detectado varios síndromes como el ITSO (Inability-to-switch-off) o incapacidad para desconectar; así como el FOMO (Fear of MissingOut), o miedo a sentirse fuera de onda o desconectado.

Los síntomas de tales patologías son, como cabría esperar: depresión, ansiedad, insomnio, hipertensión, problemas de concentración, disminución de la capacidad de socialización, e incluso ataques de pánico o episodios psicóticos (Young, 2014: 18).

\section{Conclusión:}

\section{El zoon elektronikón ¿una nueva transformación de la humanidad?}

En cualquier caso, se puede comprobar que los postulados aristotélicos fundamentales, su holismo primigenio y el protagonismo del lenguaje, continúan estando vigentes, más allá de su descentramiento patriarcal y sociológico, así como de la re-vertebración de su clasismo inmóvil.

Pues, en efecto, la neurociencia social no ha dejado de insistir en la dimensión zoon del ser humano, constituyendo ésta la base de todo desarrollo posterior: la animalidad 
humana implicaría su humanidad. Y su humanidad no sería sino la prolongación natural de su animalidad: "La experiencia moral ha surgido como instinto, aunque se nos manifieste como una esfera autónoma y objetiva" (Castro Nogueira, 2008: 62).

Así mismo, la supervivencia del individuo humano estaría sujeta a la supervivencia del grupo que lo ha acogido, lo acoge y lo acogerá hasta su muerte. Aquí también la animalidad específica del ser humano sería incomprensible sin el grupo, de manera que será zoon politikón o no será, ya que, dadas sus características, en otras circunstancias no sobreviviría.

Y, por otro lado, por mucho que cambien los soportes, y aun con las distinciones que se puedan hacer entre ellos, el lenguaje, aun con todo lo deteriorado que se pueda manifestar, siempre dará fe de una peculiar forma de animalidad que no es sino humanidad: zoon éjon lógon.

Teniendo en cuenta lo anteriormente expuesto, puede surgir un amplio abanico reflexivo acerca del futuro del ser humano si persiste esta nueva deriva encauzada por el zoon elektronikón.

Así, y en primer lugar, parece necesario aceptar la evidencia de las transformaciones que se están produciendo, por mucho que en principio trastornen los modelos (ideales) de ser humano que se han esbozado hasta ahora. En este sentido, la mera constatación de la diversidad socio-cultural de la humanidad, puesta ahora de manifiesto más claramente por la Sociología del Conocimiento y la globalización debería ser una buena pista.

Por ejemplo, la crítica, por otro lado posiblemente justa, de que las TIC reducen en muchos casos el feed-back multi-sensorial al feed-back electrónico, debería tener en cuenta que la sociedad occidental ha priorizado tradicionalmente el sentido de la vista sobre todos los demás sentidos, a diferencia de otras sociedades, como la china, en las que "este sesgo sensorial no se perfila con tanta nitidez" (Lizcano, 1996: 1).

En segundo lugar, surge la duda de si los instrumentos de evaluación de que disponemos, la mayor parte de ellos generados a lo largo del siglo XX pero con importantes sesgos metodológicos del siglo anterior, son capaces de dar cuenta de las trasformaciones que se están produciendo. Se debe reflexionar sobre si todavía se pueden mantener afirmaciones como que "la capacidad de abstraer fue una etapa crítica en la adquisición eficiente del conocimiento y probablemente vino de alguna manera impuesta al cerebro por las limitaciones de su sistema de memoria, ya que este nuevo mecanismo desecha la necesidad de recordar cada detalle" (Mora, 2009: 125). Pues, por ejemplo, ya no se puede mantener una articulación cerebral zonificada y definitiva. En este sentido, es muy posible que, como ha apuntado Timothy Taylor, los cambios tecnológicos reseñados estén generando un nuevo modelo de inteligencia; un nuevo modelo en el que paradójicamente "los humanos tenderán a ser biológicamente menos inteligentes, o sea, criaturas biotecnológicas, lo que no necesariamente es algo negativo" (Sáez Vacas, 2011: 2).

Se debería revisar, por lo tanto, a la vista de los recientes descubrimientos neurocientíficos, cuestiones como la dinámica de la comprensión conceptual, la atención o la memoria, a pesar de que los primeros datos indican que, más allá de tópicos generalizados, los dispositivos tecnológicos no facilitan la "capacidad para el pensamiento ininterrumpido" ya que, por ejemplo, "captar el significado de los textos 
complejos requiere la concentración en una sola tarea de atención constante, no el salto entre distintas tareas que caracteriza las comunicaciones digitales" (Sousa, 2014: 39).

Y, por fin, en tercer lugar, sería bueno meditar acerca de los nuevos modelos de socialidad que se deducen del estrecho vínculo del zoon elektronikón con las TIC, pues no por nuevos deben ser necesariamente mejores pero tampoco peores. Al fin y al cabo, los seres humanos se han ido adaptando poco a poco a las transformaciones que la naturaleza o la propia sociedad han ido generando.

Pues, en efecto, el proceso de humanización no puede comprenderse sin el grupo, pero tampoco sin la progresión en la postura erecta -que aplastó las manos de las extremidades inferiores convirtiéndolas en pies- y la consecuente bipedestación, ocurrida hace unos seis millones de años, ni sin la elongación de la tráquea -que permitió el lenguaje articulado. Ni, por supuesto, sin tener en cuenta el desarrollo de determinadas zonas del cerebro como la circunvolución angular izquierda, ubicada en la zona más posterior e inferior del lóbulo parietal "que prácticamente no existe en los primates inferiores $\mathrm{y}$, si bien se insinúa en los grandes monos, es en el cerebro humano donde alcanza un aumento notable" (Redolar, 2014: 208).

Si todos estos cambios se produjeron a lo largo de miles de años, y en los últimos cuatro mil apenas sí los ha habido perceptibles, la disciplina histórica y la antropología nos indican que, desde la industrialización que se desencadenó en el siglo XIX, algunos colectivos humanos han ido modificando sus pautas de conducta adaptándose al medio ambiente físico y social.

La última transformación ha acontecido a partir de 1990, "fecha del nacimiento de la World Wide Web (www) en el CERN suizo" (Trujillo, 2014: 7) y comienzo del desarrollo de la revolución digital y de sus secuelas sociales; entre las que se cuenta el nada despreciable control informático en tiempo real (Boltanski y Chiapello, 1999), ya generalizado.

La fecha es demasiado reciente y nada podría afirmarse, en un sentido negativo, de una socialidad en la que la socialización, por muy light que sea, por mucho que no reúna los requisitos de los modelos anteriores, por más que evite la fricción de la socialización supuestamente plena, no pueda lograr la generación de microclimas sociales en los que se pueda desenvolver la vida de los individuos "con aquellos que les son próximos e indispensables emocionalmente" (Castro Nogueira, 2008: 538).

Todo ello con tal de que el humano no acabe siendo un ser "sin tribu, sin ley, sin hogar", como afirma una y otra vez Aristóteles.

\section{Bibliografía}

Anders, G. (2011): La obsolescencia del hombre (Vol. II): Sobre la destrucción de la vida en la época de la tercera revolución industrial, Valencia, Pre-Textos.

Aristófanes. (1986): Las Asambleistas, Barcelona, Bosch.

Aristóteles. (1982): Obras: Del Alma, Ética Nicomáquea. Ética Eudemiana, Política, Constitución de Atenas. Poética, Madrid, Aguilar.

Aristóteles. (1986): Politica, Madrid, Alianza Editorial.

Aranzádi, J. (1991): "El círculo y la recta”, La(s) otra(s) historia(s), 3, pp.71-105. 
Bachiller, R. (2015): "Sobre <Revolución:del homo sapiens al homo digitalis> de Román Cendoya" Disponible en : http://www.elmundo.es/opinion/(2015)/04/22/5537d316e2704ef0498b4570.html [Consulta del 10 de junio de 2015].

Bauman, Z. (2013): Vida Líquida, Madrid, Austral.

Block de Behar, L. (2009): Medios, pantallas y otros lugares comunes. Sobre los cambios e intercambios verbales y visuales en tiempos mediáticos, Buenos AiresMadrid, Katz.

Boltanski, L. y E. Chiapello. (1999): Le nouvel esprit du capitalisme, Paris, Gallimard. Bourdieu, P. (1997): Capital Cultural, Escuela y Espacio Social, Madrid, Siglo XXI.

Castro Nogueira. L. y L. Castro Nogueira y M. Á. Castro Nogueira. (2008): ¿Quién teme a la naturaleza humana?, Madrid, Tecnos.

Carr, N. (2011): Superficiales. ¿Qué está haciendo Internet con nuestras mentes? Madrid, Taurus.

Criado, M. Á. (2015): “¿Hacia una era digital oscura?”, El País Domingo, 1 de marzo, pp.6-7.

Decety, J, y J. T. Cacioppo (eds): (2011): The Oxford Handbook of Social Neuroscience, New York, Oxford University Press.

Descartes, R. (1986): El discurso del método, Madrid, Alhambra.

De Kerckhove, D. (1999): La piel de la cultura. Investigando la nueva realidad electrónica, Barcelona, Gedisa.

D’Huy, P. (2007): "PowerPoint, la rhétorique universelle", Medium, 11, pp.12-25.

Durkheim, É. (1988): Las reglas del método sociológico, Madrid, Alianza Editorial.

Feito, L. (2007): "Las neuronas espejo", Tendencias21, Disponible en: http://www.tendencias21.net/Las-neuronas-espejo-nos-ayudan-a-comprender-lasintenciones-de-los-otros_a1498.html [Consulta de 15 de marzo de 2013].

Fincher, D. (2010): The social network. Columbia-Sony Pictures. [TSN]

Foucault, M. (1970): La arqueología del saber, México, Siglo XXI.

Frommer, F. (2011): El pensamiento PowerPoint. Ensayo sobre un programa que nos vuelve estúpidos, Barcelona, Península.

Gómez Arboleya, E. (1952): "La pólis y el saber social de los helenos" Revista de Estudios Políticos, 65, pp.49-83.

Halbwachs, M. (1994): Les Cadres Sociaux de la Mémoire, Paris, Albin Michel.

Hegel, G. W. F. (1968): Filosofía del Derecho, Buenos Aires, Claridad.

Hegel, G. W. F. (1982): Lecciones sobre filosofia de la historia universal, Madrid, Alianza Editorial.

Heidegger, M. (1982): El ser y el tiempo, Madrid, Fondo de Cultura Económica.

Huici Urmeneta, Vicente. (2007): Espacio, tiempo y sociedad (Variaciones sobre Durkheim, Halbwachs, Gurvitch, Foucault y Bourdieu, Madrid, Akal.

Huici Urmeneta, V. (2013): "Neurosociología: cerebro e interacción social". Actas del XI Congreso Español de Sociología, pp.157-162.

Iriarte Goñi, A. (2002): De amazonas a ciudadanas: pretexto ginecocrático y patriarcado en la Grecia Antigua, Madrid, Akal.

Kosko, B. (2000): El futuro borroso o el cielo en un chip, Barcelona, Crítica. 
Lafuente, A. (2007): El carnaval de la tecnociencia, Madrid, Gadir.

Lapassade, G. (1971): L'analyseur et l'analyste, Paris, Gauthier Villars.

Leung, L. (2007): Etnicidad virtual. Raza, resistencia y world wide web, Barcelona, Gedisa.

Lizcano, E. (1996): "Ser/no Ser y Yin/Yang/Tao: dos maneras de sentir, dos maneras de contar". Disponible en:

http://portal.uned.es/portal/page?_pageid=93,919684\&_dad=portal\&_ schema=PORTAL. [Consulta de 14 de mayo de 2013].

Lizcano, E. (2005): "La metáfora como analizador social”, Castro Nogueira, Luis et al. Metodología de las Ciencias Sociales. Una introducción crítica. Madrid, Tecnos.

López Eire, A. (2000): "Reflexiones sobre la comedia aristofánica", Myrtia, 15, pp. 69-101.

Lourau, R. (1970): L'analyse institutionnelle, Paris, Éditions de Minuit.

Marx, K. (1859): Contribución a la Crítica de la Economía Política. Disponible en: www.marxists.org/espanol/m-e/1850s/criteconpol.htm/ [Consulta: 15 de marzo de 2015].

Martínez Ojeda, B. (2006): Homo digitalis. Etnografía de la cibercultura, Bogotá, Uniandes.

Mora Teruel, F. (2009): Cómo funciona el cerebro, Madrid, Alianza Editorial.

Moreno Sardá, A. (1986): El arquetipo viril protagonista de la historia: ejercicios de lectura no androcéntrica, Barcelona, LaSal, edicions de les dones.

Moreno Sardá, A. (1988): La otra "política” de Aristóteles, Barcelona, Ikaria.

Redolar Ripoll, D. (2014): Neurociencia cognitiva, Madrid, Médica Panamericana.

Sáez Vacas, F. (2011): “Nativos digitales, inteligencia digital. ¿Homo digitalis?”. Telos (Cuadernos de comunicación e innovación),86, pp.1-3.

Scolari, C. (2004): Hacer clic. Hacia una sociosemiótica de las interacciones digitales. La memoria robada, Barcelona, Gedisa.

Serres, M. (2014): Pulgarcita., Barcelona, Gedisa.

Sousa, D. A. (ed). (2014): Neurociencia educativa, Madrid, Narcea.

Tomás de Aquino. (2001): Suma de Teología, Madrid, Biblioteca de Autores Cristianos.

Tonnies, F. (1979): Comunidad y Asociación, Barcelona: Península.

Trujillo,F. (coord.) (2014): Artefactos digitales, Barcelona, Graó.

Tufte, E. R. (2006): The Cognitive Style of PowerPoint: Pitching Out Corrupts Within, Cheshire, Graphics Press,

Turkle, S. (1984): El Segundo yo. Las computadoras y el espíritu humano, Buenos Aires, Galápago.

Turkle, S. (2010): Connected, but alone. Disponible en: $\mathrm{http}: / / \mathrm{www} . y o u$ tube.com/watch?v=t7Xr3AsBEK4 [Consulta: 2 de mayo de 2014].

Turkle, S. (2011): Alone together. Why we expect more from technology and less from each other, New York, Basic Books.

Young, K. (2014): "La sindrome dell'essere $<<$ sempre connessi $>>$ ", Giornale de Sicilia, 18/08, p.18. 